J. Dairy Sci. 95:5821-5830

http://dx.doi.org/10.3168/jds.2011-4893

(C) American Dairy Science Association ${ }^{\circledR}, 2012$.

\title{
Duodenal infusion of $\alpha$-linolenic acid affects fatty acid metabolism in the mammary gland of lactating dairy cows
}

\author{
G. Yang, ${ }^{* 1}$ D. P. Bu, ${ }^{\star 1}$ J. Q. Wang,${ }^{\star 2}$ Khas-Erdene, ${ }^{*}$ L. Y. Zhou, ${ }^{\star}$ and J. J. Loor† \\ ${ }^{*}$ State Key Laboratory of Animal Nutrition, Institute of Animal Science, Chinese Academy of Agricultural Sciences, Beijing, P. R. China 100193 \\ †Department of Animal Sciences and Division of Nutritional Sciences, University of Illinois, Urbana-Champaign 61801
}

\begin{abstract}
Increasing the concentration of $\alpha$-linolenic acid (LNA; 18:3 cis-9,cis-12,cis-15) in blood might affect fatty acid (FA) metabolism in the mammary gland of dairy cows. The objective was to determine the effects of different arterial concentrations of 18:3 cis-9,cis-12,cis- 15 (18:3n-3) achieved via duodenal infusions with LNA on mammary uptake [assessed via arterial-rectificative venous concentration (AC-RVC) differences], synthesis of FA, and mammary gland FA balance in lactating dairy cows. Four primiparous lactating Chinese Holstein cows fitted with duodenal cannulas were administered 2 treatments in a crossover design: LNA-rich FA infusion at varying concentrations $(0,100,200$, and $300 \mathrm{~g} / \mathrm{d}$ ) versus basal infusate control. Arterial concentration of $18: 3 \mathrm{n}-3$ increased quadratically (29.24, 134.1, 218.3, and $219.3 \mathrm{mg} / \mathrm{L}$ of plasma) as LNA infusion levels increased from 0 to $300 \mathrm{~g} / \mathrm{d}$. The mammary extraction rate and uptake of 18:3n-3 increased linearly as LNA infusion increased. The AC-RVC difference of total FA and 18:3n-3 increased more rapidly than arterial concentrations with all treatments. Increasing LNA infusion increased linearly the balance of 10:0 and 12:0, whereas it decreased linearly the 14:1 and 15:0 balances. Increasing arterial concentration of 18:3n-3 affects uptake and synthesis of FA in the mammary gland of lactating dairy cows. It is also suggested that the use of AC-RVC difference maybe an acceptable way to investigate mammary gland uptake and synthesis of FA.
\end{abstract}

Key words: $\alpha$-linolenic acid, mammary gland metabolism, uptake, dairy cow

\section{INTRODUCTION}

$\alpha$-Linolenic acid (LNA, 18:3 cis-9,cis-12,cis-15) can be converted into the essential FA eicosapentaenoic

Received September 1, 2011.

Accepted June 3, 2012.

${ }^{1}$ These authors contributed equally.

${ }^{2}$ Corresponding author: wang-jia-qi@263.net acid and docosahexaenoic acid in the human body. $\alpha$-Linolenic acid has been shown to reduce inflammation and may help prevent chronic diseases such as heart disease and arthritis. It is highly concentrated in the brain, which may be particularly important for cognitive and behavioral health as well as normal growth and development (Connor, 1999). Therefore, increasing the LNA content of milk fat is desirable from a consumer health standpoint. When low amounts $(0-160 \mathrm{~g} / \mathrm{d})$ of LNA were infused into the duodenum of dairy cows, the content of $18: 3$ cis-9,cis-12, cis-15 (18:3n-3) in milk fat increased linearly (Khas-Erdene et al., 2010). However, when the amount of LNA infused was increased from 300 to $400 \mathrm{~g} / \mathrm{d}$, the content of 18:3n-3 in milk fat decreased. It was unclear if gut digestion or mammary uptake of FA was responsible for the decrease in 18:3n3 content in milk fat.

Cow milk FA have 2 main origins; those with 12 carbons or less, most of 14:0, and about $50 \%$ of $16: 0$ are synthesized in the mammary gland from nutrient precursors (Smith, 1980). A minor portion of 14:0, about $50 \%$ of $16: 0$, and all 18-carbon FA (18C FA) are extracted from the arterial blood and are incorporated into milk. Postruminal infusion, which avoids ruminal biohydrogenation of unsaturated FA, significantly increases the concentration of infused FA in plasma. The change in FA composition in plasma affects both the amount and proportion of uptake and FA synthesized by the mammary gland; thus, such changes can improve the profile of milk fat (Enjalbert et al., 1998).

The effect of FA on metabolism in the mammary gland varies between different $18 \mathrm{C}$ FA. Effects of individual FA have been studied, but little is known about LNA. Arterio-venous concentration differences (AVD) is the major tool used to investigate FA metabolism in the mammary gland (Enjalbert et al., 1998; GuinardFlament et al., 2007). Because mammary gland tissue absorbs some water when extracting FA from arterial blood, venous plasma volume is smaller than arterial, which leads to an increase in the concentration of FA in venous plasma. Therefore, AVD does not reflect the true uptake of FA by the mammary gland. In the present study, arterial-rectificative venous concentration 
(AC-RVC) differences were used to investigate the effects of different arterial concentrations (AC) of LNA on uptake and synthesis of FA in the mammary gland of lactating dairy cows infused with graded levels of LNA into the duodenum.

\section{MATERIALS AND METHODS}

\section{Cows, Diets, and Experimental Procedures}

Four primiparous Chinese Holstein cows $(\mathrm{BW}=476$ $\pm 6 \mathrm{~kg}$, DIM at the beginning of the experiment $=$ $100 \pm 2$ d) fitted with duodenal cannulas were used in a crossover design. The T-type duodenal cannula had a 2.5-cm center diameter (Bar Diamond, Parma, ID). The surgical method used was that of Komarek et al. (1981). Cows were housed and milked in individual tie-stalls in an environmentally controlled barn. Fresh water was provided for ad libitum consumption from individual drinking cups. The lactation diet (Table 1) was fed as TMR twice daily at 0700 and $1900 \mathrm{~h}$ in an amount to ensure ad libitum intake. Orts were removed and weighted once daily. Cows were milked twice daily at 0500 and $1700 \mathrm{~h}$ and allowed to exercise after milking for about $3 \mathrm{~h}$ daily.

Treatments consisted of homogenized aqueous mixtures of FFA or a control (CON) containing only the emulsifying ingredients. Treatments were administered by duodenal infusion to avoid ruminal biohydrogenation of unsaturated FA. The CON infusate consisted of $15 \mathrm{~g} / \mathrm{d}$ of xanthan gum (Fufeng Fermentation Co. Ltd., Shandong, China), $5 \mathrm{~g} / \mathrm{d}$ of sodium alginate (Qingdao Bright Moon Seaweed Group Co., Qingdao, China), and $25 \mathrm{~g} / \mathrm{d}$ of Tween 80 (Sigma Chemical Co., St. Louis, MO) in $10 \mathrm{~L}$ of drinking water. The LNA infusate contained the same ingredients as the control plus LNA (Linuo Biochem Co. Ltd., Anyang, Henan, China) at 0, $100,200,300$, or $400 \mathrm{~g} / \mathrm{d}$. The LNA mixture contained (weight basis) $82.4 \% 18: 3$ cis-9, cis-12, cis-15, 14.7\% 18:2 cis-9,cis-12, $2.8 \% 18: 1$ cis- 9 , and $0.1 \%$ other FA.

The experiment lasted for $11 \mathrm{wk}$, including a 1-wk preliminary period, two 4-wk experimental periods, and a 2-wk washout period (Table 2). During each week of a 4 -wk experimental period, the 2 cows of the infusion group received a $0-, 100-, 200-$, or $300-\mathrm{g} / \mathrm{d}$ LNA infusion sequentially, whereas the 2 control cows received only the basal infusate at the same volume for the entire $4 \mathrm{wk}$. Measurements were made on the last day of each infusion week. At the end of first 4-wk experimental period, all cows were infused with water for a 2-wk washout period to eliminate carryover of the previous infusion before being switched to the other treatment for period 2. We recorded feed intake and milk yield daily during the whole experiment including
Table 1. Ingredient and composition of the basal diet on a DM basis $(\%)$

\begin{tabular}{lc}
\hline Item & \% of DM \\
\hline Ingredient & \\
Alfalfa hay & 10.0 \\
Chinese wild hay & 25.0 \\
Corn silage & 15.0 \\
Corn & 23.0 \\
Wheat bran & 3.5 \\
Soybean meal & 10.5 \\
Cottonseed meal & 5.5 \\
Rapeseed meal & 4.0 \\
Calcium carbonate & 1.2 \\
Calcium phosphate, dibasic & 1.3 \\
Salt & 0.5 \\
Mineral-vitamin premix & 0.5 \\
Total & 100.0 \\
Composition & \\
NE ${ }^{2}$ Mcal/kg of DM & 1.50 \\
DM, \% & 62.4 \\
CP, \% of DM & 18.5 \\
NDF, \% of DM & 41.0 \\
ADF, \% of DM & 27.0 \\
EE, \% of DM & 3.10 \\
Ca, \% of DM & 0.95 \\
P, \% of DM & 0.64
\end{tabular}

${ }^{1}$ Contained 5,500 mg of $\mathrm{Fe} / \mathrm{kg}, 4,080 \mathrm{mg}$ of $\mathrm{Cu} / \mathrm{kg}, 17,500 \mathrm{mg}$ of $\mathrm{Zn} /$ $\mathrm{kg}, 4,980 \mathrm{mg}$ of $\mathrm{Mn} / \mathrm{kg}, 110 \mathrm{mg}$ of Se/kg, $180 \mathrm{mg}$ of I/ $\mathrm{kg}, 88.5 \mathrm{mg}$ of $\mathrm{Co} / \mathrm{kg},>2,000 \mathrm{IU}$ of vitamin $\mathrm{A} / \mathrm{g}, 600 \mathrm{IU}$ of vitamin $\mathrm{D}_{3} / \mathrm{g}$, and 10.8 $\mathrm{mg}$ of vitamin $\mathrm{E} / \mathrm{g}$.

${ }^{2}$ Calculated according to China NY/t 34 standard (Ministry of Agriculture of People's Republic of China, 2004).

${ }^{3}$ Ether extract.

the washout period, which helped determine that the length of the washout period was appropriate. Furthermore, we also statistically analyzed 2 groups of data with amounts of $0 \mathrm{~g} / \mathrm{d}$ in periods 1 and 2, considering cows as the fixed effect; results showed no difference in DMI, daily milk yield, milk composition, and even FA concentration in milk fat.

Infusion solutions were prepared daily in a manner similar to the procedure of Drackley et al. (2007). The ingredients were mixed and heated to $72^{\circ} \mathrm{C}$ in steamjacketed stainless steel vats and were then homogenized into stable emulsions with a homogenizer (model APV 1000; APV Manufacturing Poland Sp. z o.o., Bydgoszcz, Poland) at 17.2 MPa during the first stage and 3.5 $\mathrm{MPa}$ during the second stage. Homogenized mixtures were cooled and stored at $4^{\circ} \mathrm{C}$ until use. Each day, the appropriate amount of infusion solution for each cow was weighted into tared buckets and infused over a 20 -h period. Solutions were continuously infused into the duodenum with peristaltic pumps (model 205U; Watson-Marlow Pumps, Falmouth, Cornwall, UK), via Norprene food tubing (number 06402-14; Cole-Parmer Instrument Co., Vernon Hills, IL) that passed through the rubber of the duodenal cannula. 
Table 2. Scheme of experimental design and application of treatments ${ }^{1}$

\begin{tabular}{|c|c|c|c|c|c|c|c|c|c|c|c|}
\hline \multirow[b]{2}{*}{ Cow } & \multicolumn{11}{|c|}{ Amount of LNA infused, $\mathrm{g} / \mathrm{d}$} \\
\hline & $\frac{\text { Preliminary }}{\text { wk }-1}$ & wk 1 & wk 2 & wk 3 & wk 4 & wk 5 & wk 6 & wk 7 & wk 8 & wk 9 & wk 10 \\
\hline 490 & $\mathrm{~W}$ & 0 & 100 & 200 & 300 & W & W & 0 & 0 & 0 & 0 \\
\hline 639 & W & 0 & 100 & 200 & 300 & W & W & 0 & 0 & 0 & 0 \\
\hline 466 & W & 0 & 0 & 0 & 0 & W & W & 0 & 100 & 200 & 300 \\
\hline
\end{tabular}

${ }^{1} \mathrm{LNA}=\alpha$-linolenic acid; $\mathrm{W}=$ cows were infused with water only. For $0 \mathrm{~g} / \mathrm{d}$ of LNA, cows received the carrier in water (control).

Infusion procedures were essentially as described previously (Enjalbert, et al., 1998). The infusion line was passed through an orifice in the duodenal cannula, which remained securely attached during infusions. The patency of the infusion line was checked automatically by examining the change in weight for each infusate while it sat on an electronic balance (model TC05; Mettler-Toledo International Inc., Changzhou, Jiangsu, China). The patency of the infusion lines was checked twice daily, and any leakage problems were fixed if encountered.

\section{Sample Collection}

Milk samples were collected twice daily at 0500 and $1700 \mathrm{~h}$ on the last day of each infusion amount. Milk samples were collected in the morning stored at $4^{\circ} \mathrm{C}$ and then composited with the sample collected at 1700 $\mathrm{h}$ stored at $-20^{\circ} \mathrm{C}$ until analysis.

The coccygeal vein/artery (representing mammary arterial supply) and caudal epigastric veins (milk vein) were used for blood sampling (Cant et al., 1993a). On the last day of each infusion, blood samples were collected at 0630 and $1130 \mathrm{~h}$ into $10-\mathrm{mL}$ heparinized tubes [5,000 United States Pharmacopeia (USP) units of heparin/L of whole blood]. Arterial and venous samples were obtained almost simultaneously. They were centrifuged at $3,000 \times g$ for $15 \mathrm{~min}$ at $4^{\circ} \mathrm{C}$ after collection and plasma samples were frozen at $-20^{\circ} \mathrm{C}$ until analysis.

\section{Analytical Procedures}

Plasma FA taken up from arterial blood by mammary gland tissues are mainly NEFA released from circulating triglycerides (TG) via the action of lipoprotein lipase. To consider all FA taken up by the mammary gland, the total FA from plasma lipids were measured. Fatty acids in plasma were extracted and methylated with a 1-step procedure (Palmquist and Jenkins, 2003) after addition of 17:0 (Sigma-Aldrich Chimie, Saint Quentin Fallavier Cedex, France) as an internal standard. The total FA in $2 \mathrm{~mL}$ of milk was extracted using diethyl ether/hexane and transesterified to FA methyl ester using freshly prepared methanolic sodium methoxide (Shingfield et al., 2008).

Separation of FA was achieved using a gas chromatograph (model 6890 series II; Hewlett Packard Co., Avondale, PA) fitted with a flame-ionization detector. Samples containing FA methyl esters in hexane $(2 \mu \mathrm{L})$ were injected through the split injection port (50:1) onto an SP-2560 fused silica $100-\mathrm{m} \times 0.25-\mathrm{mm}$ column with a $0.20-\mu \mathrm{m}$ film (Supelco Inc., Bellefonte, PA). The oven temperature was initially $120^{\circ} \mathrm{C}$ for $10 \mathrm{~min}$, and then increased to $230^{\circ} \mathrm{C}$ at $1.5^{\circ} \mathrm{C} / \mathrm{min}$ and held for $30 \mathrm{~min}$. The injector and detector temperatures were maintained at $250^{\circ} \mathrm{C}$ and $300^{\circ} \mathrm{C}$; the total run time was 113 min. Heptadecadienoic acid 17:0 was used as a quantitative internal standard. Each peak was identified using known standards of FA and FA methyl esters (Nu-Chek Prep, Elysian, MN; Matreya LLC, Pleasant Gap, PA; and Supelco 37 Component FAME mix, Supelco Inc.). The percentage of each FA was calculated by dividing the area under the FA peak (minus the area under the peak for heptadecanoic acid) by the sum of the areas under the total reported FA peaks.

\section{Calculation and Statistical Analysis}

Mammary gland tissue absorbs some water when extracting FA from arterial blood (Aukland and Reed, 1993). Some of the absorbed water goes into milk, some goes back to venous plasma via the lymphatic circulation system, and it is taken up by other tissues. Therefore, the venous volume is smaller than arterial volume, which can artificially increase the concentration of FA in venous plasma. Thus, FA extraction (\%) from arterial plasma by the mammary gland, calculated as [( $\mathrm{AC}$ - venous concentration)/AC $\times 100$, may not be accurate enough (Enjalbert et al., 1998; Guinard-Flament et al., 2007).

Rectificative venous concentration is defined as the concentration of FA in a venous plasma sample to which the water lost has been accounted for and it was calculated as follows: 

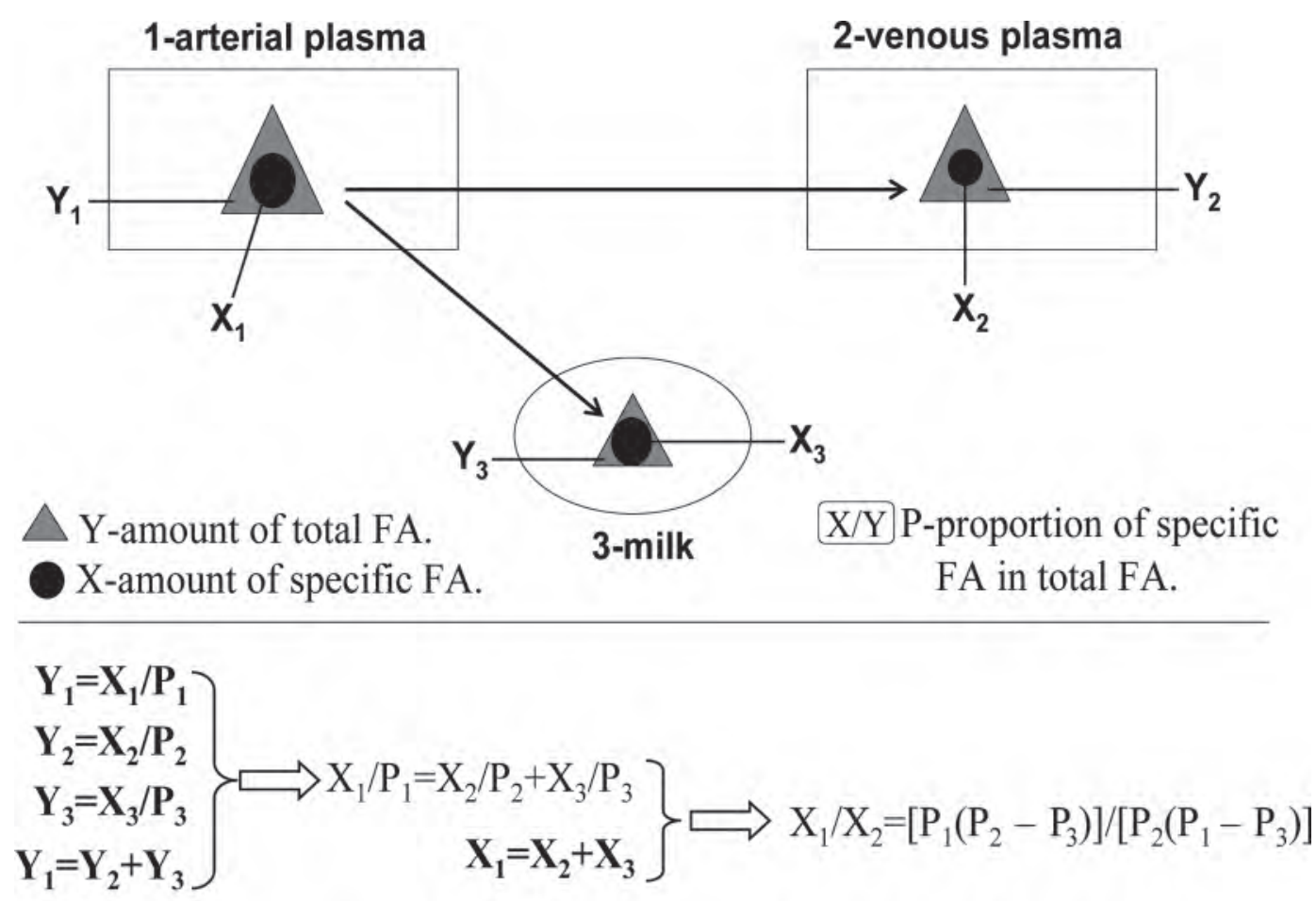

$$
\text { Then: Extraction }(\%)=\left(\mathrm{X}_{1}-\mathrm{X}_{2}\right) / \mathrm{X}_{1} \times 100=\left(\mathrm{P}_{2} \mathrm{P}_{3}-\mathrm{P}_{1} \mathrm{P}_{3}\right) /\left(\mathrm{P}_{1} \mathrm{P}_{2}-\mathrm{P}_{1} \mathrm{P}_{3}\right) \times 100
$$

Figure 1. Extraction model of FA from arterial plasma by the mammary gland. $\mathrm{Y}_{1}=$ amount of total FA in arterial plasma; $\mathrm{Y}_{2}=$ amount of total FA in venous plasma; $\mathrm{Y}_{3}=$ amount of total FA in milk; $\mathrm{X}_{1}=$ amount of specific FA in arterial plasma; $\mathrm{X}_{2}=$ amount of specific FA in venous plasma; $\mathrm{X}_{3}=$ amount of specific $\mathrm{FA}$ in milk; $\mathrm{P}_{1}=$ specific $\mathrm{FA} /$ total $\mathrm{FA}$ in arterial plasma; $\mathrm{P}_{2}=$ specific $\mathrm{FA} /$ total FA in venous plasma; $\mathrm{P}_{3}=$ specific FA/total FA in milk. To ensure that the equation $\left(\mathrm{Y}_{1}=\mathrm{Y}_{2}+\mathrm{Y}_{3}\right)$ is correct, the FA synthesized by the mammary gland from precursors, including the FA with 12 carbons or less (14:0 and 16:0), were not reckoned in total FA. Moreover, it is propitious to ensure that FA concentrations were expressed on weight basis. Five basal equations $\left(Y_{1}=X_{1} / P_{1}, Y_{2}=X_{2} / P_{2}, Y_{3}=X_{3} / P_{3}, Y_{1}=Y_{2}+Y_{3}\right.$, and $\left.X_{1}=X_{2}+X_{3}\right)$ can be set up. Then, the formula [individual FA extraction $(\%)=\left(\mathrm{P}_{2} \mathrm{P}_{3}-\mathrm{P}_{1} \mathrm{P}_{3}\right) /\left(\mathrm{P}_{1} \mathrm{P}_{2}-\mathrm{P}_{1} \mathrm{P}_{3}\right) \times 100$ ] was developed to evaluate the extraction rate of 18:0 + 18:1 cis-9 from arterial plasma by the mammary gland.

(1) Using the proportions of 18:0 + 18:1 cis-9 in arterial, venous, and milk total FA, mammary extraction $(\%)$ of 18:0 + 18:1 cis-9 was calculated using a new formula [individual FA extraction $\left.(\%)=\left(\mathrm{P}_{2} \mathrm{P}_{3}-\mathrm{P}_{1} \mathrm{P}_{3}\right) /\left(\mathrm{P}_{1} \mathrm{P}_{2}-\mathrm{P}_{1} \mathrm{P}_{3}\right) \times 100\right]$, derived in Figure 1;

(2) Rectificative venous concentration of 18:0 + 18:1 cis-9, associated with $\mathrm{AC}$ of 18:0 and 18:1 cis-9, was calculated as $\mathrm{AC} \times(1$ - extraction rate $)$ of 18:0 + 18:1 cis-9;

(3) Rectificative venous concentration of total FA associated with the proportion of 18:0 and 18:1 cis-9 in venous total FA was calculated as RVC/ proportion of 18:0 + 18:1 cis-9;

(4) Each RVC of individual FA associated with the proportion of individual FA in venous total FA was calculated as RVC of total FA $\times$ proportion of individual FA.

Extraction (\%) of each FA from arterial plasma by the mammary gland was calculated as $[(\mathrm{AC}-\mathrm{RVC}) / \mathrm{AC}]$ $\times 100$. The plasma/milk $(\mathbf{P} / \mathbf{M})$ ratio of the mammary gland was calculated as milk concentration of $(18: 0+$ 18:1 cis-9)/(AC - RVC) of 18:0 + 18:1 cis-9. Mammary plasma flow $(\mathbf{M P F}, \mathrm{L} / \mathrm{h})$ was calculated as $[(\mathrm{P} / \mathrm{M}$ ratio $) \times$ milk yield $] / 24 \mathrm{~h}$. Mammary uptake $(\mathrm{g} / \mathrm{L}$ of milk $)$ of each FA was calculated as $(\mathrm{AC}-\mathrm{RVC}) \times(\mathrm{P} / \mathrm{M}$ ratio). Mammary gland balance ( $\mathrm{g} / \mathrm{L}$ of milk) of each FA was calculated as milk concentration - mammary gland uptake. The mean chain length of synthesized FA was calculated from mammary gland balances of individual FA with 4 to 16 carbons. Moreover, because secretion and uptake of 18:0 + 18:1 cis-9 by the mammary gland were very close (Annison et al., 1967), they were used together as a marker in calculating the RVC and $\mathrm{P} / \mathrm{M}$ ratio.

Data were analyzed statistically by using PROC MIXED of SAS (version 9.1; SAS Institute Inc., Cary, NC). The model used was as described by Drackley et al. (2007) and contained the random effect of cow and fixed effects of period (i.e., the 5-wk sets of infusion amounts within each treatment type; $1 \mathrm{df}$ ), treatment 
Table 3. Least squares means and SEM for DMI, milk yield, and 18:3n-3 yield in milk for cows infused duodenally with increasing amounts of $\alpha$-linolenic acid (LNA) suspension ${ }^{1}$

\begin{tabular}{|c|c|c|c|c|c|c|c|}
\hline \multirow[b]{2}{*}{ Variable } & \multicolumn{4}{|c|}{ LNA, g/d } & \multirow[b]{2}{*}{ SEM } & \multicolumn{2}{|c|}{$\begin{array}{c}\text { Treatment by amount, } \\
P \text {-value }\end{array}$} \\
\hline & 0 & 100 & 200 & 300 & & Linear & Quadratic \\
\hline Milk yield, kg/d & $15.7(15.4)$ & $15.8(15.1)$ & $15.7(15.8)$ & $14.1(16.7)$ & $0.46(0.46)$ & 0.16 & 0.38 \\
\hline $18: 3 \mathrm{n}-3$ yield, $\mathrm{g} / \mathrm{d}$ & $2.60(2.60)$ & $50.09(4.82)$ & $96.42(2.25)$ & $124.19(2.64)$ & $7.40(7.40)$ & $<0.0001$ & $<0.0001$ \\
\hline
\end{tabular}

${ }^{1}$ Values in parentheses are LSM for cows infused with control infusate for each corresponding infusion amount.

(CON or LNA, $1 \mathrm{df}$ ), amount infused (as a subplot, 4 df), and the interaction of treatment and amount (4 df). Because of concerns about how cows would tolerate sudden changes in amounts of LNA infused, infusion amounts were administered sequentially within periods 1 and 2. Therefore, by design, the effect of amount was confounded with time (i.e., week).

In this analysis, the statistical parameter of treatment is the interaction of treatment by amount (Drackley et al., 2007; Graves et al., 2007), which here determines whether cows receiving the LNA treatment responded differently with increasing amount (i.e., wk) infused compared with CON cows. We assumed that measurements in CON cows would be essentially constant over each 5-wk infusion period. The effects of amount were tested by using the error term of cow nested within period and treatment.

To model the effects of amount and its interaction with treatment, the REPEATED statement within PROC MIXED of SAS was used. The within-subjects variation was examined by using several covariance structures, and the one yielding the lowest Akaike's information criterion was used in the analysis (Littell et al., 1998, 2000). For all variables, this was the AR(1) option. Polynomial contrasts were constructed to partition the treatment by amount interaction into single degree of freedom comparisons. The degrees of freedom were determined by using the Kenward-Roger method (Littell et al., 1996). Model residuals were examined for all variables and found to be normally distributed. Least squares means were calculated and are presented with their standard error means. Significance was declared at $P<0.05$.

\section{RESULTS}

\section{DMI, Milk Yield, and 18:3n-3 Yield in Milk}

Dry matter intake and milk yield were not affected when 0,100 , or $200 \mathrm{~g}$ of $\mathrm{LNA} / \mathrm{d}$ was infused but decreased slightly as LNA infusion increased from 200 to $300 \mathrm{~g} / \mathrm{d}$. Yield of 18:3n-3 in milk increased significantly as LNA infusion increased from 0 to $300 \mathrm{~g} / \mathrm{d}$. Dry matter intake, milk yield, and 18:3n-3 yield in milk are presented in Table 3.

\section{FA Concentration in Plasma}

Arterial concentration of 18:3n-3 increased sharply as LNA infusion increased from 0 to $300 \mathrm{~g} / \mathrm{d}$ (Table 4). The concentration of total FA tended $(P=0.12)$ to increase as LNA infusion increased to $200 \mathrm{~g} / \mathrm{d}$ but then decreased as LNA infusion increased to $300 \mathrm{~g} / \mathrm{d}$. Increasing LNA infusion decreased the concentration of 18:2 cis-9, cis-12 linearly. The concentration of $18: 1$ cis-9 tended $(P=0.11)$ to decrease as LNA infusion increased. Palmitic acid was not affected by LNA infusion. Effects on venous concentration of FA were the same as those on AC (Table 4).

\section{Mammary Gland Extraction of Arterial FA}

The 18:3n-3 and 18:2 cis-9,cis-12 extraction rates from arterial plasma by mammary gland increased linearly by LNA infusion (Table 4). The extraction rates of total $\mathrm{FA}, 16: 0,18: 0$, and 18:1 cis-9 were not significantly affected by LNA infusion. A general trend toward higher mammary gland extraction rates was observed when the AC of total FA increased. This trend was supported by the regression between $\mathrm{AC}$ of total $\mathrm{FA}$ as an independent variable and the AC-RVC difference of total FA with all treatments. The relationship between these 2 variables had a quadratic component, with the slope representing the rate of extraction of arterial total FA increasing with AC (Figure 2).

Similar relationships were observed between AC and AC-RVC differences of 18:3n-3, 18:0 (Figure 3 and Figure 4). These relationships were confirmed by significant correlation coefficients between AC and extraction rates of FA (Table 5). The significant correlation coefficients between $\mathrm{AC}$ of 16:0 or 18:0 and extraction rates of 16:0, 18:0, 18:1 cis-9, or total FA, and between $\mathrm{AC}$ of $18: 3 \mathrm{n}-3$ and extraction rates of $18: 1$ cis- $9,18: 2$ cis-9, cis-12, or total FA were observed as well. 


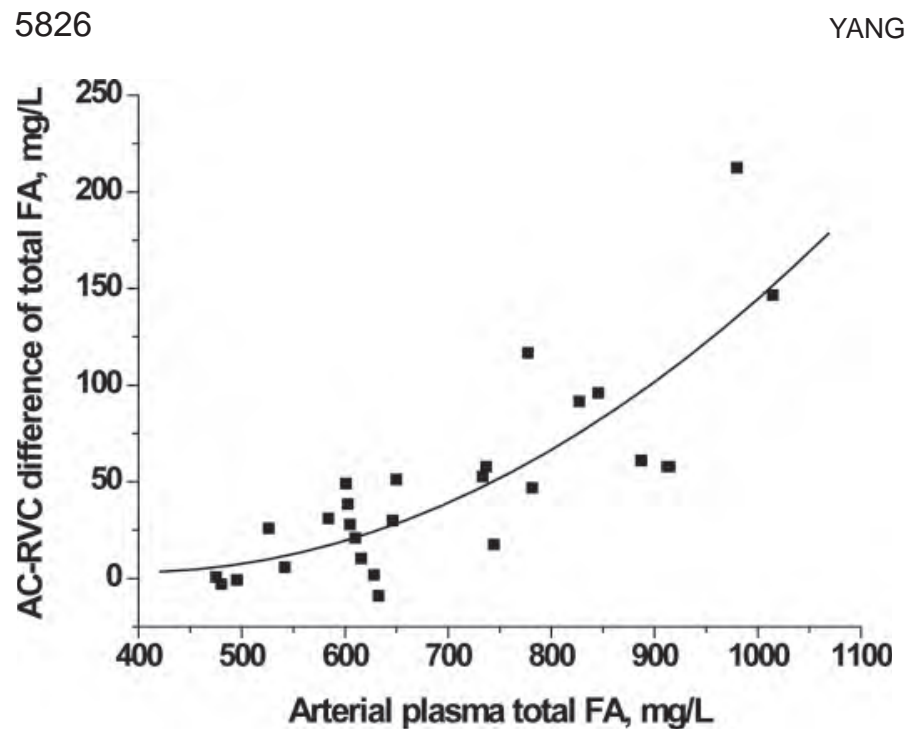

Figure 2. The regression equation $\mathrm{y}=64.02-0.307 \mathrm{x}+0.00039 \mathrm{x}^{2}$ $\left(\mathrm{R}^{2}=0.68, P<0.0001\right)$ represents the relationship between arterial plasma concentration of total FA in arterial plasma and arterialrectificative venous concentration (AC-RVC) difference of total FA in cows infused duodenally with $\alpha$-linolenic acid (LNA) and control suspensions. Values are single determinations for 4 cows administered each amount, and some preternatural dots are deleted $(\mathrm{n}=28)$.

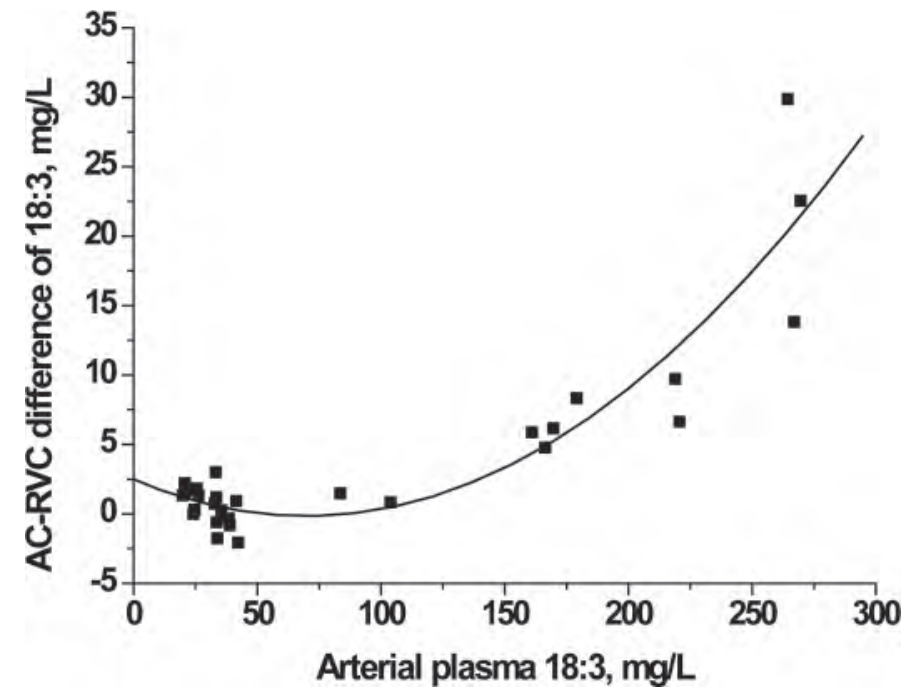

Figure 3. The regression equation $\mathrm{y}=2.47-0.0755 \mathrm{x}+0.000541 \mathrm{x}^{2}$ $\left(\mathrm{R}^{2}=0.85, P<0.0001\right)$ represents the relationship between arterial plasma concentration of 18:3n-3 in arterial plasma and arterial-rectificative venous concentration (AC-RVC) difference of 18:3n-3 in cows infused duodenally with $\alpha$-linolenic acid (LNA) and control suspensions. Values are single determinations for 4 cows administered each amount, and some preternatural dots are deleted $(\mathrm{n}=29)$.

Table 4. Least squares means and SE for plasma concentration and mammary gland extraction rates of FA in cows infused duodenally with increasing amounts of $\alpha$-linolenic acid (LNA) suspension ${ }^{1}$

\begin{tabular}{|c|c|c|c|c|c|c|c|}
\hline \multirow[b]{2}{*}{ Item } & \multicolumn{4}{|c|}{ LNA, g/d } & \multirow[b]{2}{*}{ SEM } & \multicolumn{2}{|c|}{$\begin{array}{c}\text { Treatment by amount, } \\
P \text {-value }\end{array}$} \\
\hline & 0 & 100 & 200 & 300 & & Linear & Quadratic \\
\hline Total FA & $623.7(607.5)$ & $740.2(561.2)$ & $813.8(650.8)$ & $710.4(670.7)$ & $59.2(59.2)$ & 0.99 & 0.12 \\
\hline $16: 0$ & $69.48(67.58)$ & $71.14(54.23)$ & $75.29(73.77)$ & $65.66(77.65)$ & $8.32(9.50)$ & 0.25 & 0.50 \\
\hline $18: 0$ & $101.1(98.1)$ & $113.3(95.03)$ & $115.2(105.6)$ & $96.0(107.0)$ & $10.5(10.5)$ & 0.82 & 0.33 \\
\hline $18: 3 n-3$ & $29.24(29.15)$ & $134.1(26.04)$ & $218.3(31.35)$ & $219.3(30.44)$ & $12.4(12.4)$ & 0.0014 & 0.0003 \\
\hline \multicolumn{8}{|l|}{$\mathrm{RVC}^{3}{ }^{3} \mathrm{mg} / \mathrm{L}$} \\
\hline Total FA & $594.6(578.3)$ & $706.3(550.0)$ & $750.6(619.9)$ & $639.3(629.6)$ & $47.0(47.0)$ & 0.85 & 0.09 \\
\hline $16: 0$ & $65.12(63.18)$ & $70.85(65.10)$ & $64.84(68.29)$ & $58.93(66.82)$ & $4.86(4.86)$ & 0.25 & 0.98 \\
\hline $18: 0$ & $90.09(87.44)$ & $101.7(87.07)$ & $99.52(92.97)$ & $81.56(94.11)$ & $7.18(7.18)$ & 0.30 & 0.30 \\
\hline $18: 1$ cis -9 & $53.08(52.42)$ & $32.35(50.64)$ & $26.24(57.50)$ & $20.80(54.78)$ & $6.17(6.17)$ & 0.0075 & 0.048 \\
\hline 18:2 cis-9,cis-12 & $292.7(284.5)$ & $305.9(259.9)$ & $297.9(305.4)$ & $221.1(314.3)$ & $20.8(20.8)$ & 0.023 & 0.23 \\
\hline $18: 1$ cis- 9 & $13.26(14.14)$ & $22.50(16.87)$ & $29.26(11.43)$ & $25.14(15.52)$ & $6.91(6.62)$ & 0.29 & 0.26 \\
\hline $18: 2$ cis -9, cis -12 & $1.36(0.75)$ & $2.17(2.74)$ & $3.00(-0.35)$ & $8.91(2.59)$ & $1.33(2.80)$ & 0.011 & 0.63 \\
\hline $18: 3 n-3$ & $2.33(2.01)$ & $2.70(1.22)$ & $3.87(4.14)$ & $7.66(3.70)$ & $2.34(2.53)$ & 0.016 & 0.28 \\
\hline
\end{tabular}

${ }^{1}$ Values in parentheses are LSM for cows infused with control infusate for each corresponding infusion amount.

${ }^{2}$ Arterial concentration of FA.

${ }^{3}$ Rectificative venous concentration of FA.

${ }^{4}$ Extraction (\%) of FA from arterial plasma by mammary gland, calculated as $[(\mathrm{AC}-\mathrm{RVC}) / \mathrm{AC}] \times 100$. 
Table 5. Correlation coefficients between arterial concentration (AC) of FA and mammary gland extraction (\%) in cows infused duodenally both with $\alpha$-linolenic acid (LNA) and control

\begin{tabular}{llllccc}
\hline & \multicolumn{7}{c}{ Mammary extraction, $\%$} \\
\cline { 2 - 7 } AC, $\mathrm{mg} / \mathrm{L}$ & $\mathrm{C} 16: 0$ & $\mathrm{C} 18: 0$ & $18: 1$ cis-9 & $18: 2$ cis-9, cis-12 & C18:3n-3 & Total \\
\hline $\mathrm{C} 16: 0$ & $0.79^{* * * *}$ & $0.79^{* * *}$ & $0.56^{* *}$ & 0.12 & -0.18 & $0.81^{* * *}$ \\
$\mathrm{C} 18: 0$ & $0.66^{* * *}$ & $0.73^{* * *}$ & $0.69^{* * *}$ & 0.19 & -0.017 & $0.77^{* * *}$ \\
$18: 1$ cis-9 & 0.35 & $0.42^{*}$ & $0.37^{*}$ & -0.14 & -0.22 & $0.45^{*}$ \\
$18: 2$ cis-9, cis-12 & $0.51^{* *}$ & 0.36 & $0.45^{*}$ & -0.03 & 0.03 & $-0.49^{* *}$ \\
C18:3n-3 & 0.20 & 0.37 & $0.56^{* *}$ & $0.64^{* * *}$ & $0.41^{*}$ & $0.45^{* *}$ \\
Total & $0.62^{* * *}$ & $0.66^{* * *}$ & $0.75^{* * *}$ & $0.37^{*}$ & 0.03 & $0.74^{* * *}$ \\
\hline
\end{tabular}

${ }^{*} P<0.05 ;{ }^{* *} P<0.01 ;{ }^{* * *} P<0.001$

\section{Mammary Gland Uptake}

Uptake of 18:3n-3 by the mammary gland increased linearly by LNA infusion (Table 6). Uptake of total FA by the mammary gland was not significantly affected by LNA infusion $(P=0.17)$.

\section{Mammary Gland Balance}

Increasing LNA infusion decreased linearly the balance of 14:0, 14:1, 15:0, and 16:0 (Table 6). The mean chain length of FA synthesized by the mammary gland was not affected by LNA infusion.

Some correlation coefficients between mammary gland uptake of 18:3n-3 and mammary gland balance of FA were significant with LNA and CON (Table 7). They confirmed the lower synthesis of 14:1, 15:0, and 16:0, and the greater synthesis of 10:0 and 12:0 when higher amounts of 18:3n-3 were taken up by the mammary gland. The total balance of FA was negatively correlated with the uptake of 18:3n-3.

\section{DISCUSSION}

As expected, we observed an increase in AC, mammary gland uptake, and 18:3n-3 yield in milk by duodenal infusion of LNA. This allowed for the study of the effect of 18:3n-3 on mammary gland metabolism of FA, and validated our calculation method of FA uptake by the mammary gland.

\section{Plasma Concentrations}

As in previous studies, higher plasma concentration of infused FA was observed when the amount of LNA infused increased. In a previous study, higher plasma concentrations of TG and NEFA were observed in cows receiving 30 to $90 \mathrm{~g}$ of fat $/ \mathrm{kg}$ in the diet as calcium soaps of FA (Choi and Palmquist, 1996). Significantly higher plasma TG and NEFA were observed in midlactation cows after duodenal infusion of rapeseed oil (Gagliostro et al., 1991). A nonsignificant increase of arterial total FA was observed in our trial. Such an increase was a result of greater 18:3n-3 concentration in arterial plasma. Moreover, the 300- versus $200-\mathrm{g} / \mathrm{d}$ LNA infusion did not produce higher AC of 18:3n-3. One reason for this response is that the digestibility of 18:3n-3 was reduced (data not shown) when $300 \mathrm{~g}$ of $\mathrm{LNA} / \mathrm{d}$ was infused. In fact, slight diarrhea occurred in almost all cows infused with $300 \mathrm{~g}$ of LNA/d.

\section{Mammary Gland Extraction Rates}

Extraction (\%) of 18:0 + 18:1 cis-9 from arterial plasma by the mammary gland was calculated as $\left(\mathrm{P}_{2} \mathrm{P}_{3}\right.$ $\left.-\mathrm{P}_{1} \mathrm{P}_{3}\right) /\left(\mathrm{P}_{1} \mathrm{P}_{2}-\mathrm{P}_{1} \mathrm{P}_{3}\right) \times 100$. This formula takes into account the proportion of individual FA in arterial, venous, and milk total FA. Because the concentration of FA was not used directly, calculations of extraction

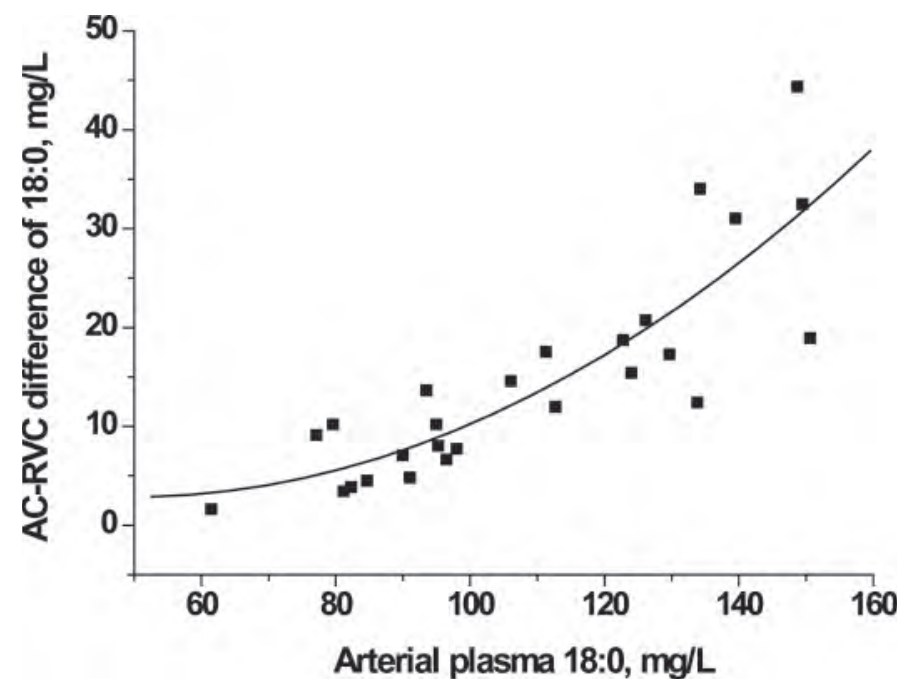

Figure 4. The regression equation $\mathrm{y}=9.92-0.2856 \mathrm{x}+0.00289 \mathrm{x}^{2}$ $\left(\mathrm{R}^{2}=0.73, P<0.0001\right)$ represents the relationship between arterial plasma concentration of 18:0 in arterial plasma and arterial-rectificative venous concentration (AC-RVC) difference of 18:0 in cows infused duodenally with $\alpha$-linolenic acid (LNA) and control suspensions. Values are single determinations for 4 cows administered each amount, and some preternatural dots are deleted $(\mathrm{n}=26)$. 
Table 6. Mammary gland uptake and balance of FA in cows infused duodenally with increasing amounts of $\alpha$-linolenic acid (LNA) suspension ${ }^{1}$

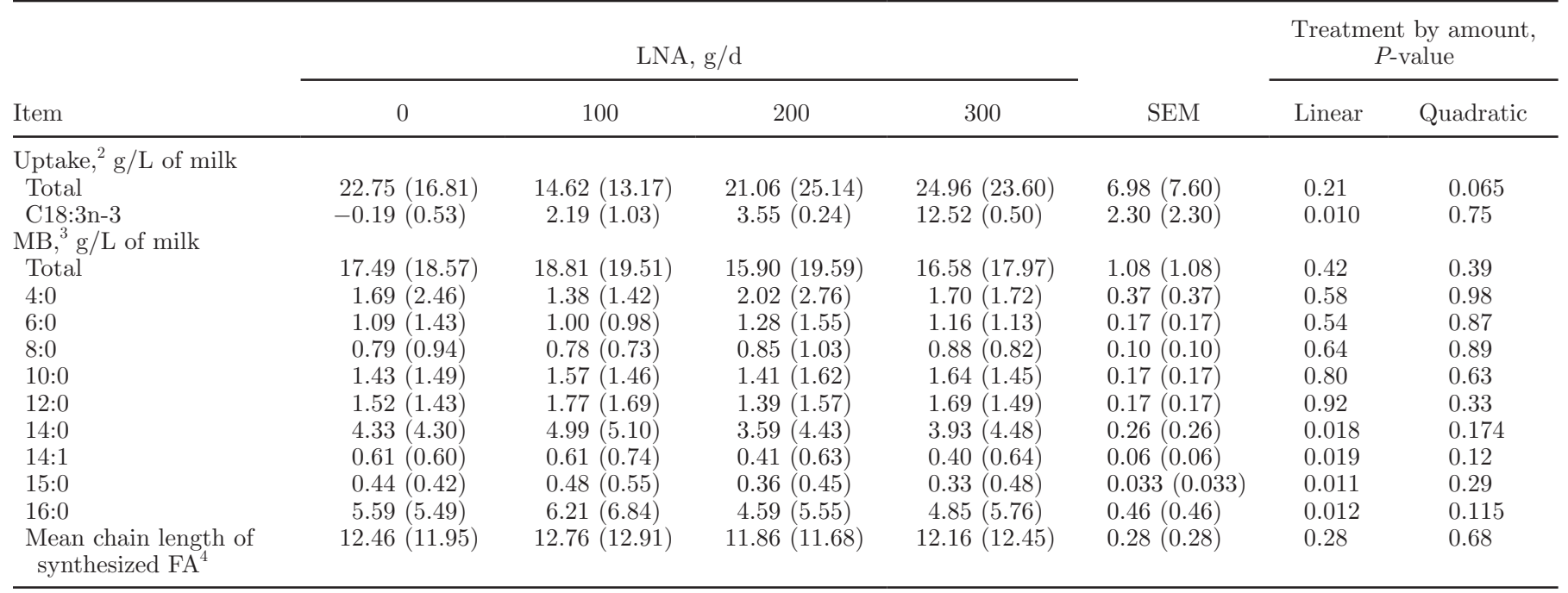

${ }^{1}$ Values in parentheses are LSM and SE for cows infused with control infusate for each corresponding infusion amount.

${ }^{2}$ Mammary gland uptake of FA from arterial plasma (g/L of milk).

${ }^{3}$ Mammary gland balance (g/L of milk), calculated as milk concentration - mammary gland uptake.

${ }^{4}$ Mean chain length of synthesized FA was calculated from mammary gland balances of individual FA with 4 to 16 carbons.

rates avoided 2 errors. The first one represents a physiological error because mammary gland tissue absorbs some water when extracting FA from arterial blood and, thus, venous volume becomes smaller than arterial volume, which can result in greater concentrations of FA in venous plasma leading to arterio-venous differences that are smaller than the true value. The other error represents a measurement error associated with the fact that FA in samples were extracted with hexane and methylated before being quantified by gas chromatography. It is difficult to have uniform extraction rates of $\mathrm{FA}$ in different batches, and the concentrations of FA in samples quantified by gas chromatography were likely not close to the actual values, and the loss of water in plasma does not alter the proportion of individual $\mathrm{FA}$ contained in the total $\mathrm{FA}$ of venous plasma. Because the extraction rate of each individual FA in the same sample was very close, the proportion of individual FA in the total FA pool could be exactly calculated as individual/total FA concentration. Thus, use of the proportion of individual FA in total FA to calculate FA extraction rates by the mammary gland was deemed appropriate.

$\alpha$-Linolenic acid infusion changed FA extraction rates through affecting AC of FA and MPF. The AVD of total TG and NEFA depend on AC, with very different slopes published in the scientific literature. For example, Cant et al. (1993b), Gagliostro et al. (1991), and Miller et al. (1991) found slopes of 0.29, 0.68, and 0.81 , respectively, for TG, and $0.21,0.48$, and 0.30 , respectively, for NEFA, but these authors did not explore the quadratic relationship between AC and AVD that was reported by Enjalbert et al. (1998). In our experiment, the quadratic relationships were more significant for 18:3n-3, 18:0, 16:0, and total FA, which indicated that extraction rates by mammary gland increased with $\mathrm{AC}$ of these FA. Moreover, correlations existed between $\mathrm{AC}$ of one FA and extraction rate of other FA, which

Table 7. Correlation coefficients between mammary gland uptake and balance of 18:3n-3 in cows infused duodenally both with $\alpha$-linolenic acid (LNA) and control

\begin{tabular}{ccccccccccccc}
\hline & \multicolumn{10}{c}{ MB $^{2}$} \\
\cline { 2 - 12 } Uptake $^{1}$ & Total & C4:0 & C6:0 & C8:0 & C10:0 & C12:0 & C14:0 & C14:1 & C15:0 & C16:0 & Mean ${ }^{3}$ \\
\hline $18: 3 n-3$ & $-0.32^{*}$ & -0.22 & -0.16 & -0.031 & $0.41^{*}$ & $0.48^{*}$ & -0.18 & $-0.48^{*}$ & $-0.55^{* *}$ & $-0.35^{*}$ & -0.031 \\
\hline
\end{tabular}

${ }^{1}$ Mammary gland uptake of FA from arterial plasma ( $\mathrm{g} / \mathrm{L}$ of milk).

${ }^{2}$ Mammary gland balance (g/L of milk), calculated as milk concentration - mammary gland uptake.

${ }^{3}$ Mean chain length of synthesized FA, calculated from mammary gland balances of individual FA with 4 to 16 carbons.

${ }^{*} P<0.05 ;{ }^{* *} P<0.01$. 


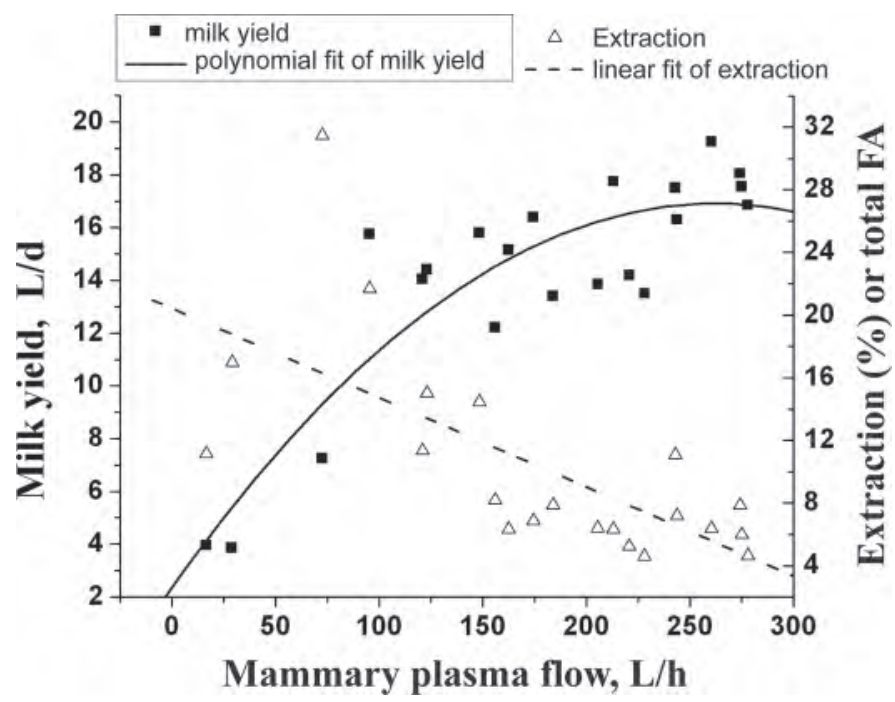

Figure 5. The regression relationships between mammary plasma flow (MPF) and milk yield, and extraction (\%) of total FA from arterial plasma by the mammary gland in lactating dairy cows infused duodenally with $\alpha$-linolenic acid (LNA) or control suspensions. Values are single determinations for 4 cows administered each amount, and some preternatural dots are deleted $(\mathrm{n}=21)$. The regression equation $\mathrm{y}=2.37+0.11 \mathrm{x}-0.000212 \mathrm{x}^{2}\left(\mathrm{R}^{2}=0.78, P<0.0001\right)$ represents the relationship between $\mathrm{MPF}$ and milk yield, and the regression equation $\mathrm{y}=20.43-0.057 \mathrm{x}(\mathrm{r}=-0.68, P=0.0007)$ represents the relationship between MPF and extraction (\%) of total FA.

suggested a degree of coordination between different FA when they are taken up from arterial plasma by the mammary gland.

Linear relationships between MPF and extraction rate of total FA were explored (Figure 5) in our experiment. A higher extraction rate of FA was achieved by lower MPF. Thus, extraction rates of FA from arterial plasma by the mammary gland depended on the $\mathrm{AC}$ of FA and MPF.

\section{Mammary Gland Synthesis of FA}

Because oxidative degradation of FA is negligible in the mammary gland, biosynthesis of FA with less than 18 carbons can be measured through mammary gland balance (Annison et al., 1967). In our experiment, mammary uptake of 18:3n-3 was significantly increased by LNA infusion, which affected synthesis of FA in the mammary gland. The total FA synthesized by the mammary gland decreased with mammary uptake of 18:3n-3, which suggested an inhibition effect on initiation of FA synthesis when the amount of 18:3n-3 taken up by the mammary gland increased (i.e., when concentration in plasma was greater).

The balance of individual FA was significantly modified by LNA infusion, but duodenal infusion of LNA did not affect the 4:0 and 6:0 balance. The correlation between 18:3n-3 uptake and the balance of 4:0 and 6:0 was not significant. Banks et al. (1990) and Beaulieu and Palmquist (1995) observed enrichment in milk fat 4:0 in vivo with fat-supplemented diets. Hansen and Knudsen (1987) found more 4:0 produced by dispersed bovine mammary gland cells with palmitate or oleate addition in vitro. Barbano and Sherbon (1980) suggested that a large diglyceride pool of high molecular weight, resulting from incorporation of exogenous longchain FA, might result in a larger output of 4:0 in milk to maintain fluidity of milk fat at body temperature. Enjalbert et al. (1998) confirmed that such a compensatory effect is more important with 16:0 or 18:0 than with 18:1 cis-9 (which has a lower melting point). Focant et al. (1998) found that oleic acid (18:1 cis-9) could improve butter spreadability. Because 18:3n-3 has a lower melting point than 18:1 cis-9, biosynthesis of 4:0 and 6:0 likely did not need to be enhanced when LNA was infused into the duodenum in our experiment. On the contrary, a negative correlation trend $(P=0.18)$ between 18:3n-3 mammary gland uptake and balance of 4:0 was observed (Table 7 ).

Lower synthesis of FA with more than 12 carbons did not produce a decrease of the mean chain length of synthesized FA. Because the balance of short-chain FA tended to decrease and the proportions of 14:1 and 15:0 in milk fat were very low, the mean chain length of synthesized FA by the mammary gland was not affected by LNA infusion.

\section{Yield of 18:3n-3 in Milk}

Because the yield of $18: 3 n-3$ in milk was calculated as milk yield $\times$ concentration of $18: 3 n-3$, milk yield was a major and direct determinant of yield of 18:3n-3. With MPF decreasing, milk yield decreased quadratically (Figure 5), which suggested that milk yield was regulated by MPF. The decrease in MPF produced by increasing milking intervals reduced milk yield and mammary uptake of nutrients in dairy cows (Delamaire and Guinard-Flament, 2006). Götze et al. (2010) found that both milk yield and mammary blood flow increased linearly as DIM increased from 14 to $84 \mathrm{~d}$ in lactating dairy cows. These results suggest that mammary blood flow plays a role in the regulation of milk yield to meet the needs of the neonate during the whole lactation. Thus, we confirmed that MPF was one essential determinant of yield of 18:3n-3 in milk.

A concurrent effect existed of increasing LNA infusion on DMI and milk yield (Table 3), which suggested that the decrease in DMI induced a depression of milk yield via decreasing MPF. Fasting reduces mammary blood flow, and it was proposed that the fraction of cardiac output that perfuses the udder of lactating ruminants 
plays a role in regulation of nutrient partitioning between milk and body tissues (Davis and Collier, 1985). Moreover, the increase in extraction rate of 18:3n-3 produced by MPF depression could not compensate for the decrease in the total amount of 18:3n-3 taken up by the mammary gland during a day.

\section{CONCLUSIONS}

Increasing the AC of 18:3n-3 affects mammary gland metabolism of FA. The extraction rate of $18: 3 \mathrm{n}-3$ by the mammary gland increased linearly with $\mathrm{AC}$ and led to inhibition of FA synthesis but enhanced production of FA with 12 carbons. The use of AC-RVC difference is a suitable approach to study mammary gland uptake and synthesis of FA. These results may be of value when developing practical management strategies to enhance milk fat LNA and the nutritional value of milk as a whole.

\section{ACKNOWLEDGMENTS}

This work was supported by the National Key Basic Research Program of China (Beijing, China; no. 2011CB100805). The authors thank Richard Kellems (Plant and Animal Sciences Department, Brigham Young University, Provo, UT) for helpful suggestions during the writing of the manuscript.

\section{REFERENCES}

Annison, E. F., J. L. Linzell, S. Fazakerley, and B. W. Nichols. 1967. The oxidation and utilization of palmitate, stearate, oleate and acetate by the mammary gland of the fed goat in relation to their overall metabolism, and the role of plasma phospholipids and neutral lipids in milk-fat synthesis. Biochem. J. 102:637-647.

Aukland, K., and R. K. Reed. 1993. Interstitial-lymphatic mechanisms in the control of extracellular fluid volume. Physiol. Rev. 73:1-78.

Banks, W., J. L. Clapperton, and A. K. Girdler. 1990. Effect of dietary unsaturated fatty acids in various forms on the de novo synthesis of fatty acids in the bovine mammary gland. J. Dairy Res. 57:179-185.

Barbano, D. M., and J. W. Sherbon. 1980. Polyunsaturated protected lipid: Effect on triglyceride molecular weight distribution. J. Dairy Sci. 63:731-740.

Beaulieu, A. D., and D. L. Palmquist. 1995. Differential effects of high fat diets on fatty acid composition in milk of Jersey and Holstein cows. J. Dairy Sci. 78:1336-1344.

Cant, J. P., E. J. DePeters, and R. L. Baldwin. 1993a. Mammary amino acid utilization in dairy cows fed fat and its relationship to milk protein depression. J. Dairy Sci. 76:762-774.

Cant, J. P., E. J. DePeters, and R. L. Baldwin. 1993b. Mammary uptake of energy metabolites in dairy cows fed fat to milk protein depression. J. Dairy Sci. 76:2254-2265.

Choi, B. R., and D. L. Palmquist. 1996. High fat diets increase plasma cholecystokinin and pancreatic polypeptide, and decrease plasma insulin and feed intake in lactating cows. J. Nutr. 126:2913-2919.

Connor, W. E. 1999. $\alpha$-Linolenic acid in health and disease. Am. J. Clin. Nutr. 69:827-828.
Davis, S. R., and R. J. Collier. 1985. Mammary blood flow and regulation of substrate supply for milk synthesis. J. Dairy Sci. 68:10411058.

Delamaire, E., and J. Guinard-Flament. 2006. Increasing milking intervals decreases the mammary blood flow and mammary uptake of nutrients in dairy cows. J. Dairy Sci. 89:3439-3446.

Drackley, J. K., T. R. Overton, G. Ortiz-Gonzalez, A. D. Beaulieu, D. M. Barbano, J. M. Lynch, and E. G. Perkins. 2007. Responses to increasing amounts of high-oleic sunflower fatty acids infused into the abomasum of lactating dairy cows. J. Dairy Sci. 90:51655175 .

Enjalbert, F., M. C. Nicot, C. Bayourthe, and R. Moncoulon. 1998. Duodenal infusions of palmitic, stearic or oleic acids differently affect mammary gland metabolism of fatty acids in lactating dairy cows. J. Nutr. 128:1525-1532.

Focant, M., E. Mignolet, M. Marique, F. Clabots, T. Breyne, D. Dalemans, and Y. Larondelle. 1998. The effect of vitamin E supplementation of cow diets containing rapeseed and linseed on the prevention of milk fat oxidation. J. Dairy Sci. 81:1095-1101.

Gagliostro, G., Y. Chilliard, and M.-J. Davicco. 1991. Duodenal rapeseed oil infusion in early and midlactation cows. 3. Plasma hormones and mammary apparent uptake of metabolites. J. Dairy Sci. 74:1893-1903.

Götze, A., A. Honnens, G. Flachowsky, and H. Bollwein. 2010. Variability of mammary blood flow in lactating Holstein-Friesian cows during the first twelve weeks of lactation. J. Dairy Sci. 93:38-44.

Graves, E. L., A. D. Beaulieu, and J. K. Drackley. 2007. Factors affecting the concentration of sphingomyelin in bovine milk. J. Dairy Sci. 90:706-715.

Guinard-Flament, J., E. Delamaire, P. Lamberton, and J. L. Peyraud. 2007. Adaptations of mammary uptake and nutrient use to oncedaily milking and feed restriction in dairy cows. J. Dairy Sci. 90:5062-5072.

Hansen, H. O., and J. Knudsen. 1987. Effect of exogenous long-chain fatty acids on individual fatty acid synthesis by dispersed ruminant mammary gland cells. J. Dairy Sci. 70:1350-1354.

Khas-Erdene, J. Q. Wang, D. P. Bu, L. Wang, J. K. Drackley, Q. S. Liu, G. Yang, H. Y. Wei, and L. Y. Zhou. 2010. Short communication: Responses to increasing amounts of free $\alpha$-linolenic acid infused into the duodenum of lactating dairy cows. J. Dairy Sci. 93:1677-1684.

Komarek, R. J. 1981. Intestinal cannulation of cattle and sheep with a T-shaped cannula designed for total digesta collection without externalizing digesta flow. J. Anim. Sci. 53:796-802.

Littell, R. C., P. R. Henry, and C. B. Ammerman. 1998. Statistical analysis of repeated measures data using SAS procedures. J. Anim. Sci. 76:1216-1231

Littell, R. C., G. A. Milliken, W. W. Stroup, and R. D. Wolfinger 1996. SAS System for Mixed Models. SAS Institute Inc., Cary, NC.

Littell, R. C., J. Pendergast, and R. Natarajan. 2000. Modelling covariance structure in the analysis of repeated measures data. Stat. Med. 19:1793-1819.

Miller, P. S., B. L. Reis, C. C. Calvert, E. J. DePeters, and R. L. Baldwin. 1991. Patterns of nutrient uptake by the mammary glands of lactating dairy cows. J. Dairy Sci. 74:3791-3799.

Ministry of Agriculture of People's Republic of China. 2004. Feeding standard of dairy cattle. China NY/t 34 standard. Ministry of Agriculture of People's Republic of China, Beijing, China.

Palmquist, D. L., and T. C. Jenkins. 2003. Challenges with fats and fatty acid methods. J. Anim. Sci. 81:3250-3254.

Shingfield, K. J., S. Ahvenjärvi, V. Toivonen, A. Vanhatalo, P. Huhtanen, and J. M. Griinari. 2008. Effect of incremental levels of sunflower-seed oil in the diet on ruminal lipid metabolism in lactating cows. Br. J. Nutr. 99:971-983.

Smith, S. 1980. Mechanism of chain length determination in biosynthesis of milk fatty acids. J. Dairy Sci. 63:337-352. 